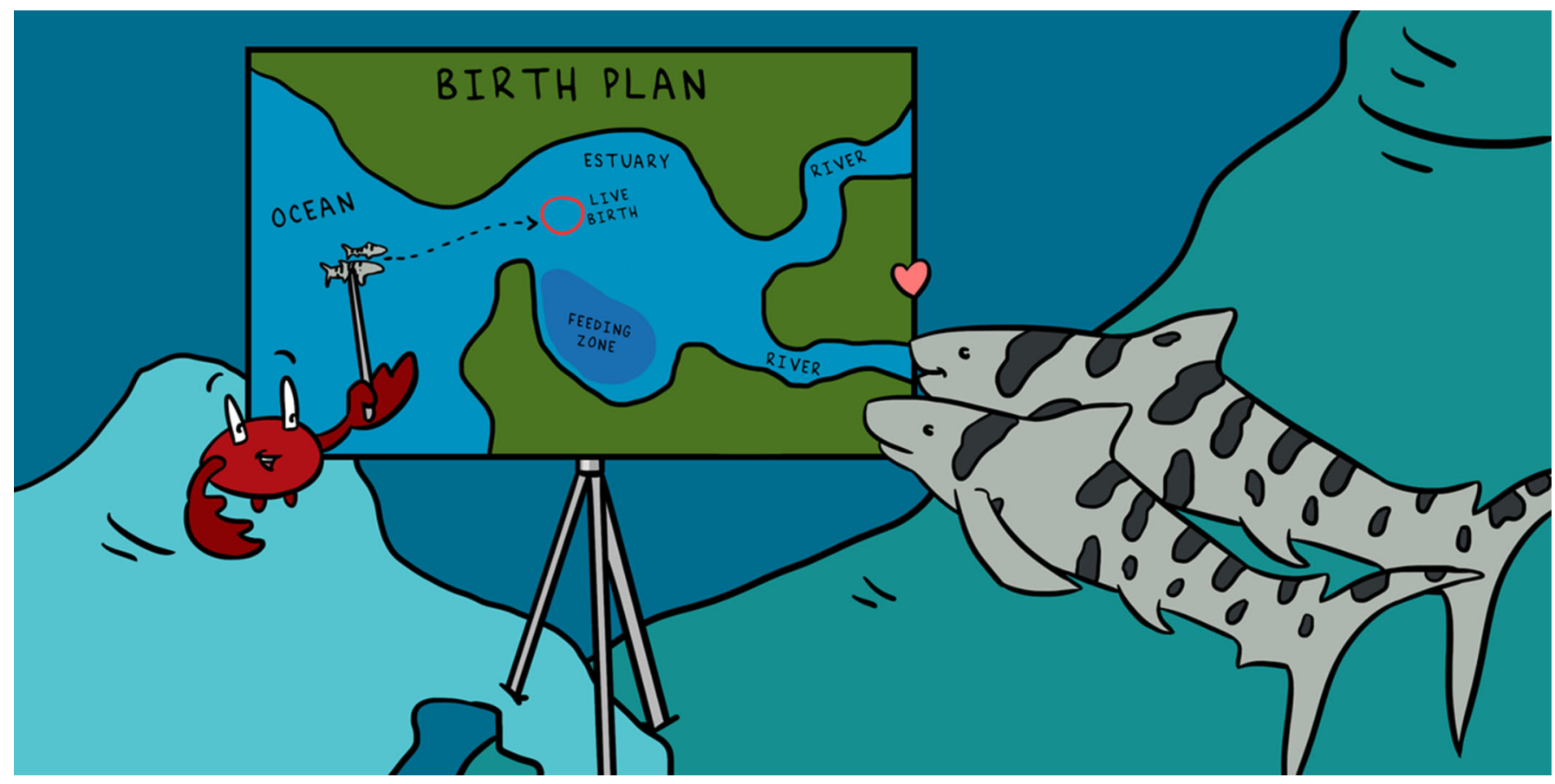

\title{
THE CLEVER STRATEGIES THAT FISHES USE TO SURVIVE IN SAN FRANCISCO'S DYNAMIC ESTUARY
}

Rachel A. Fichman ${ }^{1 *}$, Adi Khen ${ }^{2}$, Malte Willmes ${ }^{3,4}{ }^{,}$Jonathon Kuntz ${ }^{1}$, Alexander R. Scott ${ }^{1}$, James A. Hobbs ${ }^{1}$ and Levi S. Lewis ${ }^{1 *}$

${ }^{1}$ Otolith, Geochemistry and Fish Ecology Laboratory, Department of Wildlife, Fish and Conservation Biology, University of California, Davis, Davis, CA, United States

${ }^{2}$ Scripps Institution of Oceanography, University of California San Diego, La Jolla, La Jolla, CA, United States ${ }^{3}$ Institute of Marine Sciences, University of California, Santa Cruz, Santa Cruz, CA, United States

${ }^{4}$ National Marine Fisheries Service, Southwest Fisheries Science Center, Santa Cruz, CA, United States

YOUNG REVIEWERS:

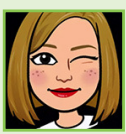

HANNAH

AGE: 11

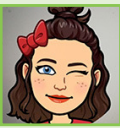

Estuaries are places where fresh water from rivers mixes with salty water from the ocean. Why does this matter? This mixing creates dynamic, ever-changing conditions that fishes must navigate in order to survive. Environmental conditions can change yearly, seasonally, daily, and even hourly. Fishes use many different strategies to adjust to this wild variation. Some are picky and only use certain habitats. Others use many different kinds of habitats and move between them at different times of the year. Adults and juveniles might even live away from each other in different parts of the estuary. In this article, we describe some of the clever strategies that fishes use to survive in estuaries. We also consider how scientists uncover these clever strategies and what each of us can do to help protect the fishes of the San Francisco Estuary and elsewhere. 
Figure 1

The San

Francisco Estuary. (A)

Fresh water from rain and snowmelt flows as rivers into a network of channels known as the Delta (riverine environment). This fresh water then mixes with the salty water of the ocean (marine environment) and creates the San Francisco Estuary (estuarine environment). (B) Salinity and temperature (in ${ }^{\circ}$ Celsius) change in the San Francisco Estuary with the seasons (left) and daily with the tides (right). Salinity in estuaries is usually between that of marine and riverine habitats, and temperatures are often between those of rivers and the ocean.

\section{RIVERINE}

Related to, found in, or produced by rivers or riverbanks.

\section{MARINE}

Related to, found in, or produced by seas or oceans.

\section{SALINITY}

The amount of salt dissolved in a body of water.
(A)

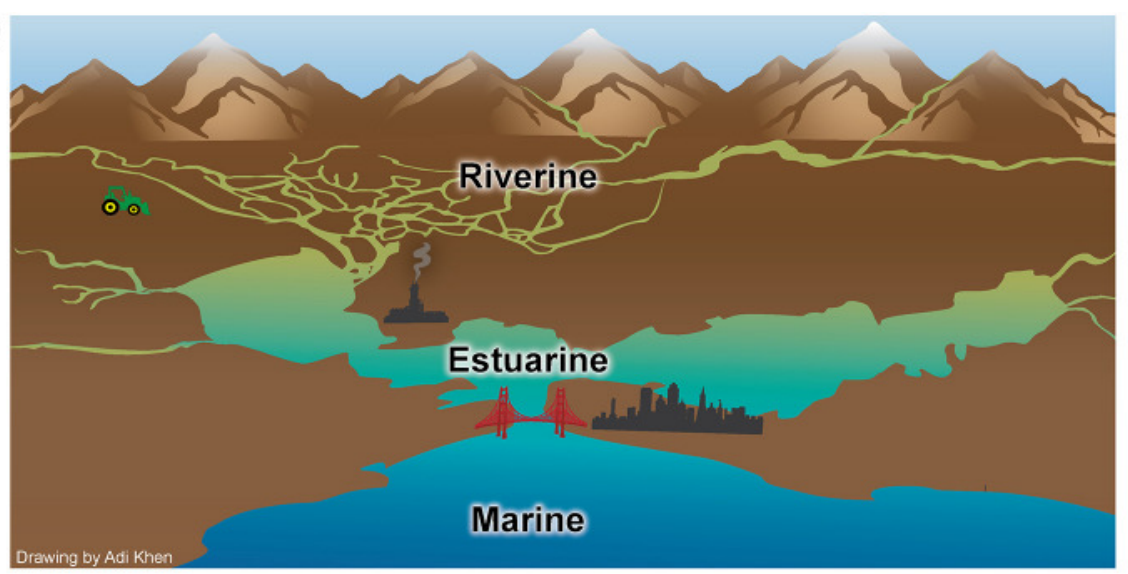

(B)

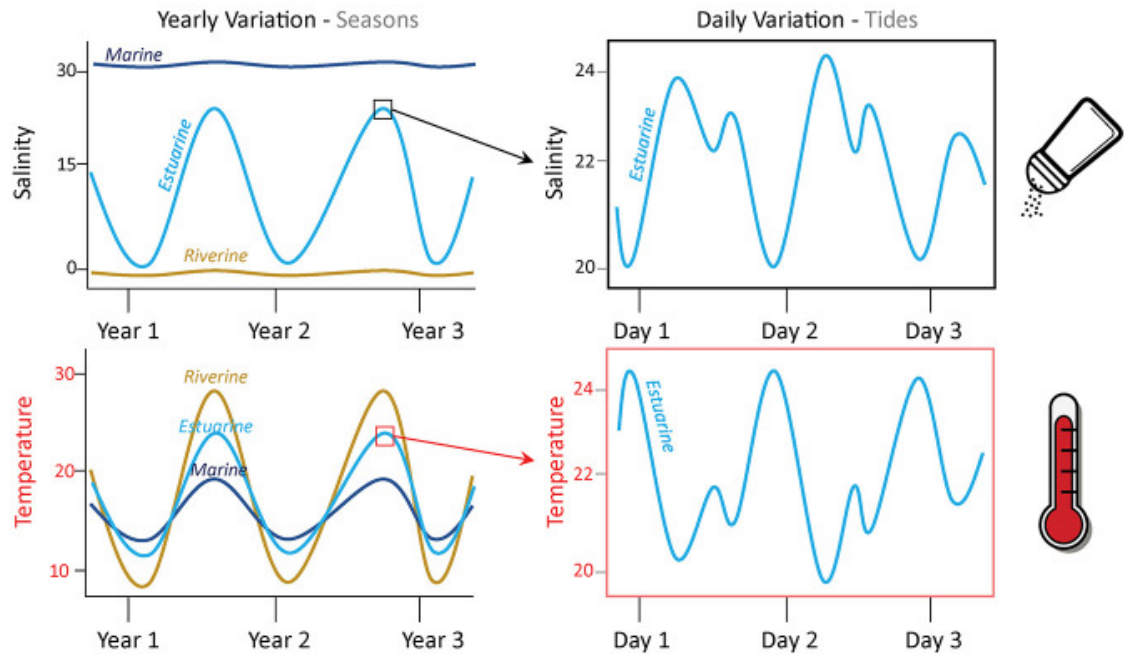

Figure 1

\section{WHY IS IT SO HARD TO LIVE IN AN ESTUARY?}

An estuary is where fresh water from rivers mixes with salty water from the ocean (Figure 1A). The furthest upstream region of an estuary is influenced most by the riverine (river-like) environment, making the water typically fresh or slightly salty. The furthest downstream region is influenced most by the marine (ocean-like) environment, so the water is often very salty. Changes in both river and ocean conditions greatly affect habitats inside estuaries, making them dynamic, ever-changing environments (Figure 1B) [1].

Salinity (saltiness) is one of the changing conditions in estuaries that fishes must deal with. The salinity of estuaries is linked to how much fresh water from rain and snowmelt flows in from rivers. In the San Francisco Estuary, winter and spring are the rainiest seasons. During these wet seasons, more fresh water flows in from rivers, making the estuary less salty. During the hotter, drier months of summer and fall, less freshwater flow results in saltier conditions. The amount of rain and snow can also change from year to year. In a dry year there is less 
1 Did you ever wonder when to use the word "fish" vs. "fishes"? "Fish" refers to one or multiple individuals of the same species. "Fishes" refers to multiple individuals of multiple species.

\section{ESTUARINE}

Related to, found in, or produced by estuaries.

\section{LIVE BIRTH}

When offspring are fully developed inside the mother and "born alive." Most fishes lay eggs in nests that are externally fertilized, but some fishes give live birth.

fresh water, making estuaries saltier. Salinity can also change daily and hourly due to the tides. High tides push saltier water further up into the estuary, whereas low tides allow rivers to push fresh water further downstream toward the ocean.

Temperature is another changeable condition within estuaries. The temperatures of estuaries vary with the seasons, getting warmer in the summer and cooler in the winter. Temperatures of inflowing rivers are often the most variable. In contrast, temperatures in the ocean are more stable. Since estuaries lie between riverine and marine habitats, their temperatures are often somewhere between the two. However, some parts of estuaries are shallow and can be rapidly heated by the hot sun during the day, while cooling off at night [1].

These constantly changing conditions make estuaries a tough place for fishes ${ }^{1}$ to live. Imagine if it were rainy 1 day, hot and sunny the next, and a blizzard the day after that. You would need to be prepared to adjust your clothing and plans at a moment's notice! Similarly, estuarine fishes have figured out many different strategies to help them deal with all this wild environmental variation.

\section{CLEVER STRATEGIES USED BY ESTUARINE FISHES}

The way a fish uses and moves between different habitats throughout its life is called its life history. Different species of fish, and even different individuals within a species, have developed unique life history strategies [2]. These differing life history strategies can be quite clever and are classified into several groups.

Freshwater stragglers, such as Sacramento suckers (Figure 2A), live and reproduce in freshwater riverine habitats. They become strong swimmers to navigate river and tidal flows. They tolerate variable temperatures, but strongly prefer lower salinities. These fishes sometimes travel into the estuary to feed when salinity is low (spring), but otherwise avoid saltier habitats.

Marine stragglers, such as leopard sharks (Figure 2B), live and reproduce in marine habitats, including coastal areas and bays. They tolerate variable temperatures, but strongly prefer waters with higher salinity. Leopard sharks venture into the estuary to feed and to give live birth during periods of high salinity (summer) but they avoid certain regions of the estuary during periods of low salinity (winter).

Estuarine residents, such as tule perch (Figure 2C), live and reproduce entirely within the estuary. Like leopard sharks, tule perch also give live birth, but they can tolerate greater variations in salinity. This allows them to remain in the estuary year-round. 


\section{Figure 2}

Five examples of common life history strategies (A-E) that native fishes use in the San Francisco Estuary.

\section{BRACKISH}

Slightly salty water that is less salty than seawater but saltier than fresh water. Often used to describe water found in estuaries.

(A) Freshwater straggler Complete their life history in fresh water, occasionally entering the estuary during low salinity conditions.

(B) Marine straggler Complete their life history in the ocean, also entering the estuary during higher salinity conditions to feed and give birth.

\section{(C) Estuarine resident}

Complete their life history and remain in brackish waters of the estuary throughout their life.

(D) Anadromous migrant Adults lay eggs far upstream in freshwater rivers. Juveniles move quickly downstream and grow far offshore in the coastal ocean, returning several years later to their home river to reproduce.

(E) Freshwater-linked migrant

Most live in estuarine waters, migrating slightly upstream to lay eggs in tidal fresh waters. Can also complete their life history in fresh wate or low-salinity water.
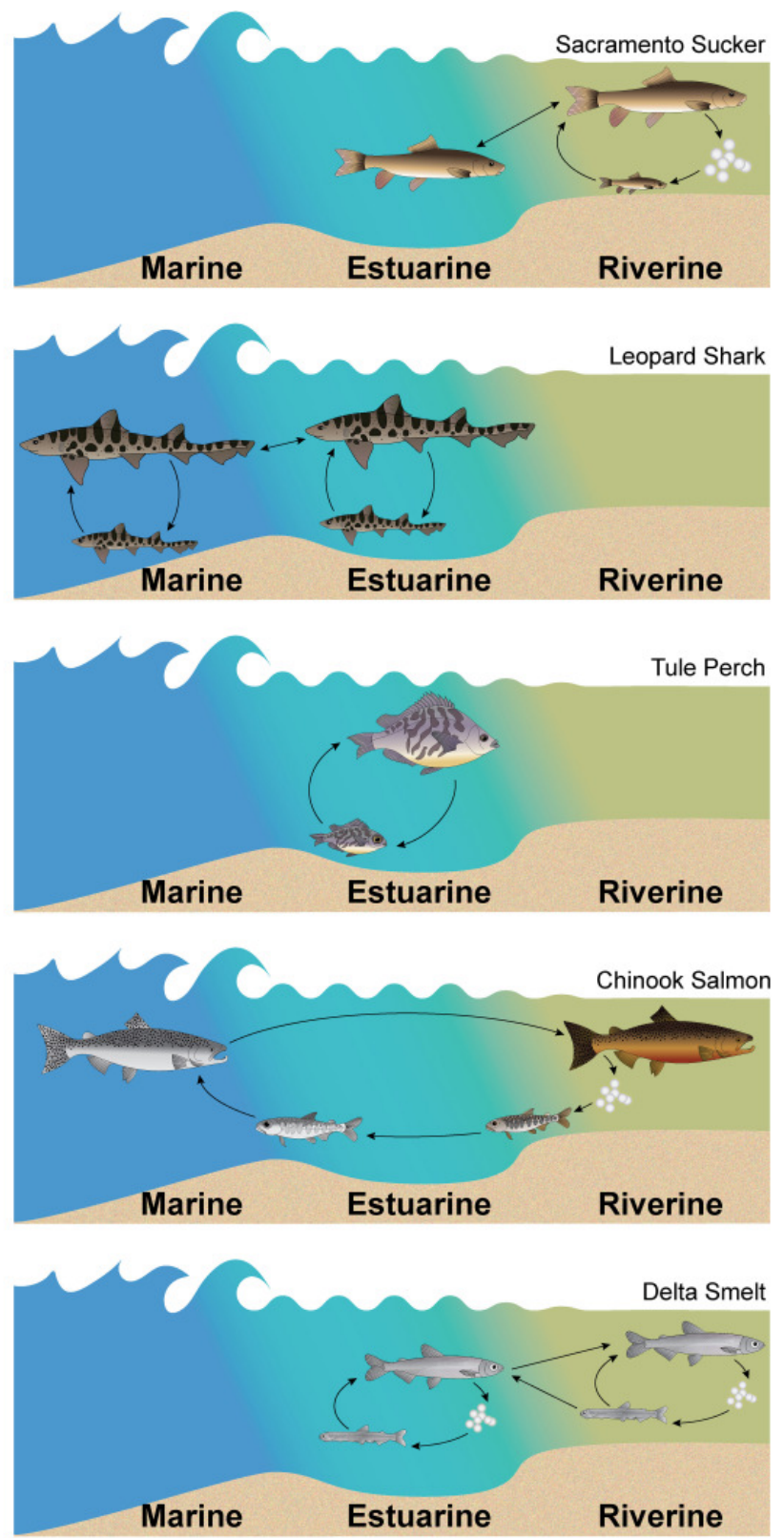

Drawings by Adi Khen

Figure 2

Anadromous migrants, such as Chinook salmon (Figure 2D), live most of their adult lives in the open ocean, migrating quickly through the estuary to lay eggs far upstream in rivers. The fish larvae and juveniles grow up in these rivers and eventually move through the estuary on their way out to the ocean, where they grow into adulthood. For this group, the estuary is like a bridge between juvenile and adult habitats.

Freshwater-linked migrants, such as delta smelt (Figure 2E), can live and reproduce in both freshwater and low-salinity estuarine environments. As juveniles, most live in the somewhat-salty (brackish) estuary during summer, migrating upstream into freshwater habitats 
Figure 3

Common methods for studying fish

movements. (A)

Surveys using nets show scientists where fishes live during different times of the year. (B) Artificial tags, such as this archival tag on a Chinook salmon, record the movements of individual fish over large distances. (C) Otolith chemistry can be used to infer where a fish lived throughout its life. For example, this delta smelt was born in riverine habitats (red star), migrated out into the salty estuary (orange star), then returned to more riverine areas later in life (yellow star). (Photo credit for B: Michael Courtney and Andy Seitz of the University of Alaska Fairbanks).

\section{FIELD SURVEY}

When researchers go outside to study plants and animals in their natural habitats, often spread out over different times, days, and locations.

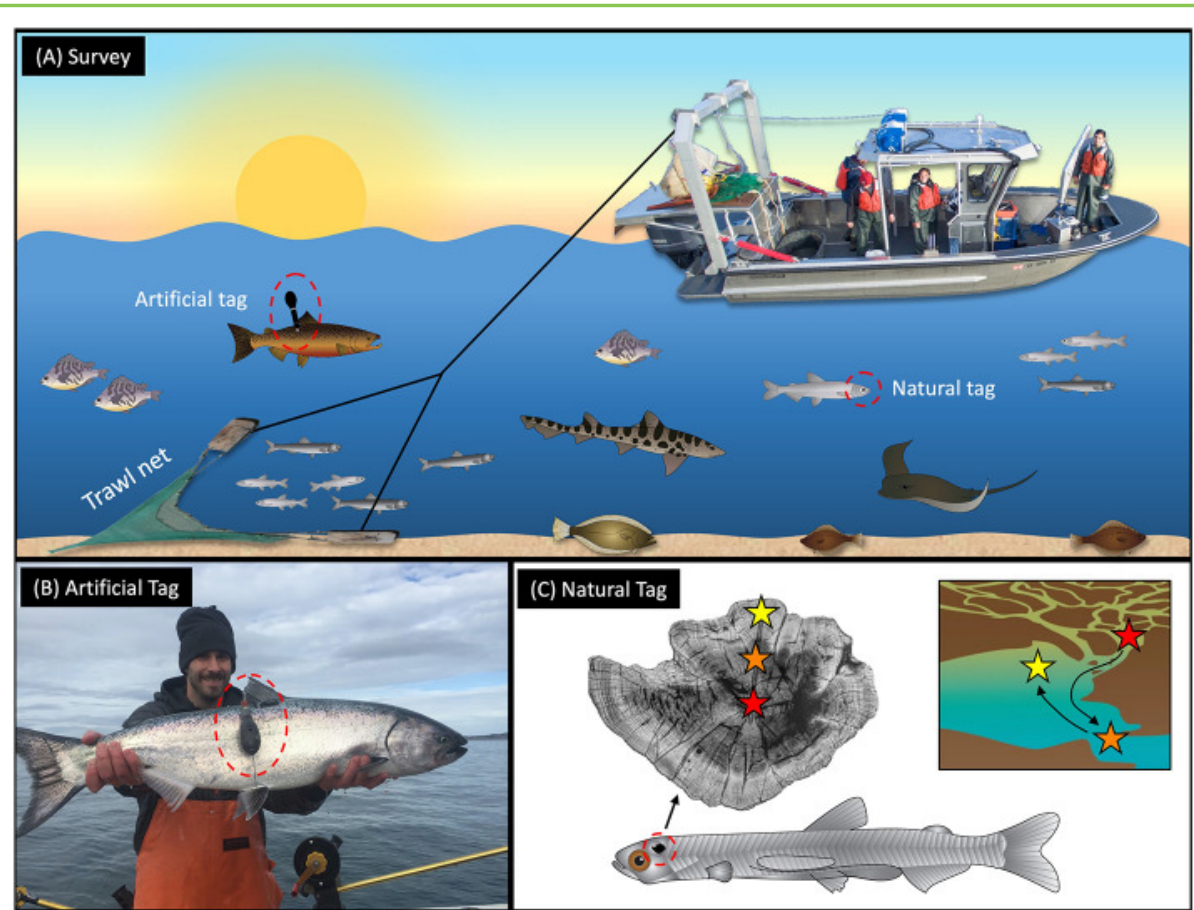

Figure 3

the following winter, as adults, to lay their eggs. Delta smelt can tolerate some variation in both temperature and salinity, but often move seasonally to find the best habitats with the most food [3].

Although different species tend to use different life history strategies, some fish within a species may not follow those strategies! For example, delta smelt are often considered a migratory species, but we found that not all individuals migrate. While most delta smelt do migrate between fresh and estuarine habitats, some spend their entire lives in either riverine or estuarine habitats. This variation is believed to help delta smelt survive unpredictable environmental stress, by making sure that some members of the species are always in different parts of the estuary [3].

\section{HOW DO SCIENTISTS STUDY THE CLEVER LIFE HISTORY STRATEGIES OF FISHES?}

Scientists use many methods to discover how fishes survive in estuaries (Figure 3). Each technique provides a different perspective on fish life history strategies.

A classic method for studying fishes in the wild is simply fishing for them (Figure 3A). These studies are called field surveys. Researchers can use different fishing approaches (hook-and-line or nets) depending on the species and habitats they want to survey. Once fishes are caught, researchers identify, count, and measure them 
before releasing them unharmed back into the water. By regularly conducting surveys, scientists can create a record of when and where fishes occur, their length and weight, and how fish populations change over time [4].

Another way to study life history is to track individual fish with artificial, human-made tags. Artificial tags allow scientists to discover how individual fish move and use different habitats. However, artificial tags require that tracking equipment be attached to each fish being studied. Some tags consist of small pieces of metal placed under a fish's skin, each with a code inscribed, so when a fish is caught, researchers can identify where it was tagged and how far it moved [4]. For larger fishes, like sharks or salmon, researchers can use archival tags that record a fish's location and environment over time (Figure 3B). Archival tags are attached to a fish's back by performing a minor surgery, similar to a large ear piercing. Once the fish has recovered, it is released back into its habitat to resume a normal life.

Instead of using artificial tags, scientists can also use the chemistry of hard, calcified body parts as natural tags to retrace the movements of fishes. Different natural tags hold different information about a fish's life. Some parts, like scales and fin spines, can be removed and the fish released, with minimal harm to the fish. But, for internal parts like otoliths, fishes must be euthanized (killed without pain or suffering) before removal. Otoliths are tiny structures that help with hearing and balance, located in the inner ear of many fishes (Figure 3C). Otoliths grow during the entire life of a fish. As they grow, chemical elements from the surrounding water are deposited into the otoliths. Scientists can then infer where a fish previously lived based on its otolith chemistry, because the chemical elements in the water of rivers, estuaries, and oceans can be very different [5]. Otoliths also grow rings, like inside a tree trunk, that reflect the age and growth of the fish. By combining otolith chemistry with otolith growth, we can even detect the timing of fish movements. This allows scientists to uncover the complex details of a species' life history [3].

\section{WHAT CAN WE DO TO HELP FISHES IN THE SAN FRANCISCO ESTUARY?}

As we have learned, fishes have developed many different strategies to thrive in an estuary. But fishes are not the only users of estuaries. Did you know that, just around the San Francisco Estuary, there are 7.8 million people? That is a lot of humans! Human activities, such as farming, city water use, and pollution, have changed estuaries across the world. This has led to the decline of many fish and wildlife populations whose clever strategies might not fit their environment anymore. Some species, like delta smelt, may even go extinct. Delta smelt are highly impacted by human activities, but we have not yet figured out how to fully protect them. Life history research helps 
2 FishBase https://www.fishbase. se/search.php

3 Aquarium of the Bay https://www.aquarium ofthebay.org/ Aquarium of the Pacific https://www.aquarium ofpacific.org/ California Academy of Sciences https://www.calacade my.org/ Monterey Bay Aquarium https://www.monterey bayaquarium.org/

4 California Fisheries Blog https://calsport.org/ fisheriesblog/ NOAA for Kids https://oceanservice. noaa.gov/kids/ Otolith, Geochemistry, and Fish Ecology Lab https://www.ogfishlab. com/

Sharks4kids https://www.sharks4 kids.com/education The Fisheries Blog https://thefisheriesblog com/

5 Ocean Conservancy https://oceanconserva ncy.org/trash-free-seas/ international-coastal-cl eanup/start-a-cleanup/ us understand where fishes are born, the habitats they use, and the timing of their migrations. Understanding the life history of fishes is a critical step toward taking action to help protect them long into the future.

This work is not just for scientists! Everyone can help scientists protect fishes in San Francisco and around the world. Here are some ways that you can help! You can find out which fishes live near you ${ }^{2}$. You can also learn more about California fishes like those in the San Francisco Estuary from aquariums ${ }^{3}$. With your new knowledge, you can teach your friends and family about the challenges that California fishes face 4 . Do you live near a waterway? If so, you can organize a beach cleanup with friends and family 5 ! And always remember to protect all the wild animals and habitats near you by being responsible in the outdoors, picking up litter, and not polluting the environment. Lastly, you can become a fish scientist and help us study and protect native fishes!

\section{ACKNOWLEDGMENTS}

Work in the Otolith, Geochemistry, and Fish Ecology Laboratory at UC Davis (www.ogfishlab.com) is conducted by numerous researchers who have all contributed to our understanding of fish life histories. We thank Andrew Seitz and Michael Courtney of the University of Alaska Fairbanks for consent to use their photo in Figure 3B. Comments from Pedro Morais and two reviewers greatly improved the manuscript.

\section{REFERENCES}

1. Cloern, J. E., and Jassby, A. D. 2012. Drivers of change in estuarine-coastal ecosystems: discoveries from four decades of study in San Francisco Bay. Rev. Geophys. 50, RG4001. doi: 10.1029/2012RG000397

2. Potter, I. C., Tweedley, J. R., Elliott, M., and Whitfield, A. K. 2013. The ways in which fish use estuaries: a refinement and expansion of the guild approach. Fish Fish 16:230-9. doi: 10.1111/faf.12050

3. Hobbs, J. A., Lewis, L. S., Willmes, M., Denney, C., and Bush, E. 2019. Complex life histories discovered in a critically endangered fish. Sci. Rep. 9:16772. doi: 10.1038/s41598-019-52273-8

4. Stompe, D. K., Moyle, P. B., Kruger, A., and Durand, J. R. 2020. Comparing and integrating fish surveys in the San Francisco estuary: why diverse long-term monitoring programs are important. San Francisco Estuary Watershed Sci. 18. doi: 10.15447/sfews.2020v18iss2art4

5. Morais, P., Dias, E., Cerveira, I., Carlson, S. M., Johnson, R., and Sturrock, A. M. 2018. How scientists reveal the secret migrations of fish. Front. Young Minds 6:67. doi: 10.3389/frym.2018.00067 
SUBMITTED: 21 September 2020; ACCEPTED: 23 July 2021;

PUBLISHED ONLINE: 23 September 2021.

EDITED BY: Pedro Morais, University of Algarve, Portugal

CITATION: Fichman RA, Khen A, Willmes M, Kuntz J, Scott AR, Hobbs JA and Lewis LS (2021) The Clever Strategies That Fishes Use to Survive in San Francisco's Dynamic Estuary. Front. Young Minds 9:608881. doi: 10.3389/frym.2021.608881

CONFLICT OF INTEREST: The authors declare that the research was conducted in the absence of any commercial or financial relationships that could be construed as a potential conflict of interest.

COPYRIGHT @ 2021 Fichman, Khen, Willmes, Kuntz, Scott, Hobbs and Lewis. This is an open-access article distributed under the terms of the Creative Commons Attribution License (CC BY). The use, distribution or reproduction in other forums is permitted, provided the original author(s) and the copyright owner(s) are credited and that the original publication in this journal is cited, in accordance with accepted academic practice. No use, distribution or reproduction is permitted which does not comply with these terms.

\section{YOUNG REVIEWERS}

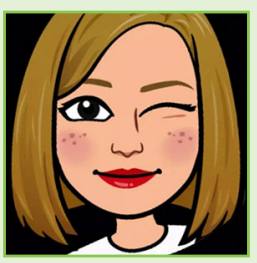

HANNAH, AGE: 11

I am in 6th grade of a middle school in Austria. I am interested in dogs. My hobbies are gymnastics, other sports, and acting. I have got an old cat and we are getting a dog soon. I also like meeting my friends and listening to some music

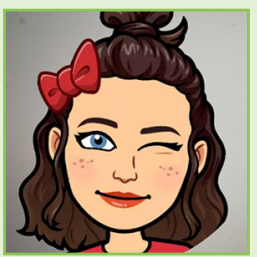

\section{VALERIE, AGE: 13}

I am in 8th grade of a middle school in Austria. My hobbies are horseback riding, skating, and dancing. I have got a very old cat and we are getting a dog soon. I also like meeting my friends and listening to some music.

\section{AUTHORS}

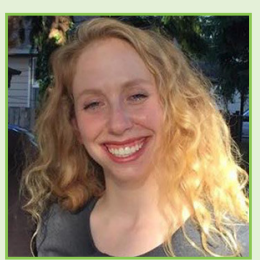

\section{RACHEL A. FICHMAN}

Rachel is a graduate student at University of California, Davis, studying conservation ecology. Through collaboration between the Otolith, Geochemistry and Fish Ecology Lab and the Freshwater Ecology Lab, Rachel studies how different environmental conditions affect body and otolith (ear stone) growth in delta smelt, a critically endangered fish endemic to the San Francisco Estuary. After graduation, Rachel looks forward to a career as a wildlife and fisheries researcher, focusing on projects that directly impact conservation policy throughout the state of California (USA). *rafichman@ucdavis.edu 

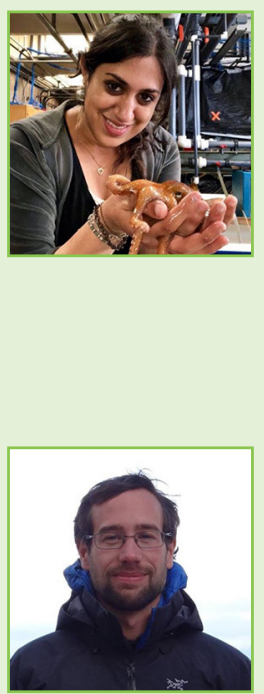

\section{ADI KHEN}

Adi is a Ph.D. candidate at the Scripps Institution of Oceanography, U.C. San Diego. She is interested in how corals and algae are responding to global climate change. She uses image analysis to measure coral bleaching, recovery, growth, and/or death over time in the context of heat stress. In addition to research, Adi is passionate about communicating science through art and she makes digital drawings of marine life in her spare time. She also loves taking care of animals and mentoring young students. You can find some of her drawings at adlysia.wordpress.com.

\section{MALTE WILLMES}

Dr. Willmes is a postdoc at U.C. Santa Cruz in the Institute of Marine Sciences and NOAA Fisheries Collaborative Program. In his research, he applies geochemical tracers to investigate habitat changes and movement patterns of different fish species, including Chinook salmon, delta and longfin smelt, and white sturgeon, to provide scientific input into their management and conservation. In his most recent project, Malte gets to combine modern fish ecology, geochemistry, and archaeology to study how ancient salmon thrived in California over the last 5,000 years.
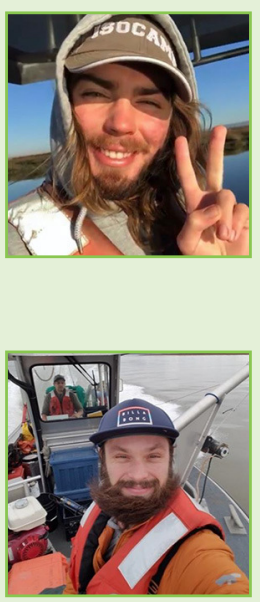

\section{JONATHON KUNTZ}

Jonathon Kuntz is a marine ecologist interested in life history research of sharks. In 2017, he received a B.Sc. in environmental and organismal biology from the University of Utah, where he used stable isotopes to study smooth hammerhead sharks. He has since worked with longfin smelt and leopard sharks, using stable isotopes to better understand their use of the San Francisco Estuary.

\section{ALEXANDER R. SCOTT}

Alec Scott, a Bay Area native, received a B.A. in biology from Carleton College, after which he spent some time doing fieldwork and becoming a divemaster in southeast Asia. He then spent a year working on coral reef ecology at the Scripps Institution of Oceanography. Most recently, he completed an M.S. in marine biology at the University of North Carolina Wilmington, where he studied distributional patterns of Caribbean mesophotic sponges. He is broadly interested in the factors that contribute to the decline of endangered species, and the policy solutions that prevent that decline.

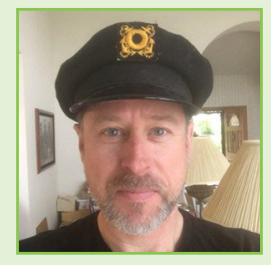

\section{JAMES A. HOBBS}

Dr. Hobbs is a researcher in the Department of Wildlife, Fish and Conservation Biology, University of California, Davis. His research program integrates long-term monitoring studies with otolith growth and geochemistry to answer important fisheries resource-management questions in the San Francisco Bay-Delta Estuary. James links population monitoring with innovative technologies to reconstruct the migration history and growth of threatened and endangered fishes. He collaborates with scientists that study genetics, fish health, and population modeling, to understand how climate change, habitat restoration, and resource-management actions affect fishes. 


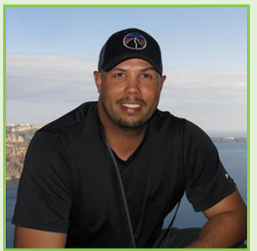

\section{LEVI S. LEWIS}

Dr. Lewis leads the Otolith Geochemistry and Fish Ecology Laboratory at U.C. Davis. $\mathrm{He}$ is a general ecologist, studying species movements, growth, and community dynamics of fishes and invertebrates in seagrass beds, coral reefs, and estuaries. His current work focuses on endangered fishes in the San Francisco Estuary, including delta smelt and longfin smelt. In addition to doing science, Dr. Lewis enjoys working with managers to improve conservation and writing "bio-rhymes" about the species and ecosystems he studies. www.accretinglife.com. *Islewis@ucdavis.edu 